\title{
MultiobJective Zone TP Reduction AnAlyses fOR AN OFF-STREAM RESERVOIR
}

\author{
By Jehng-Jung Kao, ${ }^{1}$ Associate Member, ASCE, and Cheng-Hsien Tsai ${ }^{2}$
}

\begin{abstract}
AgStRact: Multiobjective linear programming (MOLP) models are developed to evaluate total phosphorus (TP) load reduction strategies for an off-stream reservoir. Cost, water quality, and equity are the three major objectives considered. Watershed-based, subwatershed-based, and equal-transport-path-length-based strategies are the three zone control strategies analyzed and compared. The agricultural nonpoint-source pollution (AGNSP) model is used to simulate the non-point-source pollution loads on the reservoir. A twostep modeling procedure is applied to verify sediment mass balance and water quality of storm runoff. MOLP models are established based on the simulation results for the three control strategies and are solved using the ADBASE package to generate the noninferior solution sets of the models. The subwatershed-based control strategy is observed to be the most cost-effective one based on results obtained for TP concentration between 13 and $20 \mathrm{ppb}$. With respect to equity, however, the watershed-based control strategy is superior to the others. The proposed multiobjective analyses are intended to improve the comparison and evaluation of nonpoint source pollution control strategies.
\end{abstract}

\section{INTRODUCTION}

Reservoirs are important resources of drinking water in Taiwan. Protecting these bodies of water is important to maintain a sufficient water supply as well as to ensure continued social and economic development. Watershed management has therefore gained increasing attention in recent years, and environmental protection authorities have prioritized reservoir eutrophication control as a major responsibility. Contamination generated by upstream development and human activities introduces a significant amount of nutrients into a reservoir, thereby accelerating eutrophication, spoiling public water resources, and requiring costly remediation (USEPA 1992). External loads originate from point or nonpoint-source pollutants and are carried by runoff from storm events. Controlling external loads is a typical strategy to remedy the eutrophic condition. In a body of water, the amounts of nitrogen and phosphorus are generally the limiting factors of eutrophication. However, excessive nitrogen is generally available and phosphorus levels have been frequently reported [e.g., Wu et al (1990)] to be the major limiting factor of eutrophication for reservoirs in Taiwan.

Some areas in Taiwan do not have an appropriate location to build a general reservoir and have to apply the off-stream method to redirect the stream flow to a reservoir that is not on the stream network. This kind of off-stream reservoir differs from the general ones in pollution load estimation and nonpoint source pollution (NPSP) control. Pollution loads from the watershed of the reservoir as well as the loads on the input channel must be simultaneously analyzed, thereby increasing the complexity of simulation modeling. The NPSP control strategy for such an off-stream reservoir is also more complex than for a general one because, in addition to the watershed that drains directly to the reservoir, the drainage areas that drain to the input channel must be properly managed. Additional modeling efforts are therefore required for an off-stream reservoir for both pollution load estimation and NPSP control strategy evaluation.

'Prof., Inst. of Envir. Engrg, Nat. Chiao Tung Univ., Hsinchu, 75 PoAi St., Taiwan 30039, Republic of China.

${ }^{2}$ Engr., Envir. Engrg. Ctr., Nan Ya Plastics Corp., Taipei, Taiwan, ROC; formerly, Inst. of Envir. Engrg., Nat. Chiao Tung Univ., Hsinchu, 75 PoAi St., Taiwan 30039, Republic of China.

Note. Discussion open until January 1, 1998. To extend the closing date one month, a written request must be filed with the ASCE Manager of Journals. The manuscript for this paper was submitted for review and possible publication on December 11, 1995. This paper is part of the Journal of Water Resources Planning and Management, Vol. 123, No 4. July/August, 1997. CASCE, ISSN 0733-9496/97/0004-0208-0215/ $\$ 4.00+\$ .50$ per page. Paper No. 12201
Best management practices (BMPs) approaches are commonly applied to control nonpoint-source pollution. BMPs are generally divided into two types: nonstructural and structural approaches (Smolen et al. 1990). The nonstructural types reduce pollution loads by such practices as properly managing land uses and properly controlling fertilizer and pesticide applications. The structural approaches prevent pollutants by constructing permanent structures such as impoundments and sediment traps. This paper assesses several nonstructural approaches of fertilizer application controls for their effectiveness in controlling NPSP external loads for an off-stream reservoir. Previous studies have applied several optimization techniques, e.g., mixed integer programming (Kozloff et al. 1992; Ziari and McCarl 1995), dynamic programming (Bouzaher et al. 1990; Bouzaher et al. 1994), nonlinear programming (Braden et al. 1989), and stochastic programming (Milon 1987), for evaluating NPSP control strategies. However, those studies considered the cost as the primary objective in assessing NPSP control strategies. Solutions obtained from such a single objective model may be inappropriate when other objectives need to be simultaneously considered. In this work, multiobjective models are therefore developed to compare three zone NPSP control strategies. Cost, water quality, and equity, which often are contradictory, are the three objectives included in the multiobjective models. For example, significantly improving water quality requires increasing the cost to reduce NPSP loads. Furthermore, reducing pollution loads from potentially highly polluted areas is generally regarded as a cost-effective strategy, but such a strategy may not be easy to implement if all the pollutant sources are not fairly treated. Equity is therefore also an important factor in evaluating a control strategy. Mathematical models are explored in this study to analyze this multiobjective problem. The alternatives obtained by the models are intended to provide insights into the problem and hopefully assist decision makers in choosing an appropriate solution.

This paper is organized as follows. The Posan off-stream reservoir area, the studied area, is first presented. The agricultural nonpoint source pollution model (AGNPS) (Young et al. 1994), a grid-based single event model, is the nonpoint source pollution simulation model used to determine water quality impacts from each of the NPSP sources on the water body. A two-step verification of AGNPS results for the study area is then briefly summarized. Next, the three zone NPSP control strategies and the proposed multiobjective models for assessing the effectiveness of the strategies are described. The noninferior solutions of applying the multiobjective models for the study area are finally compared and analyzed. 


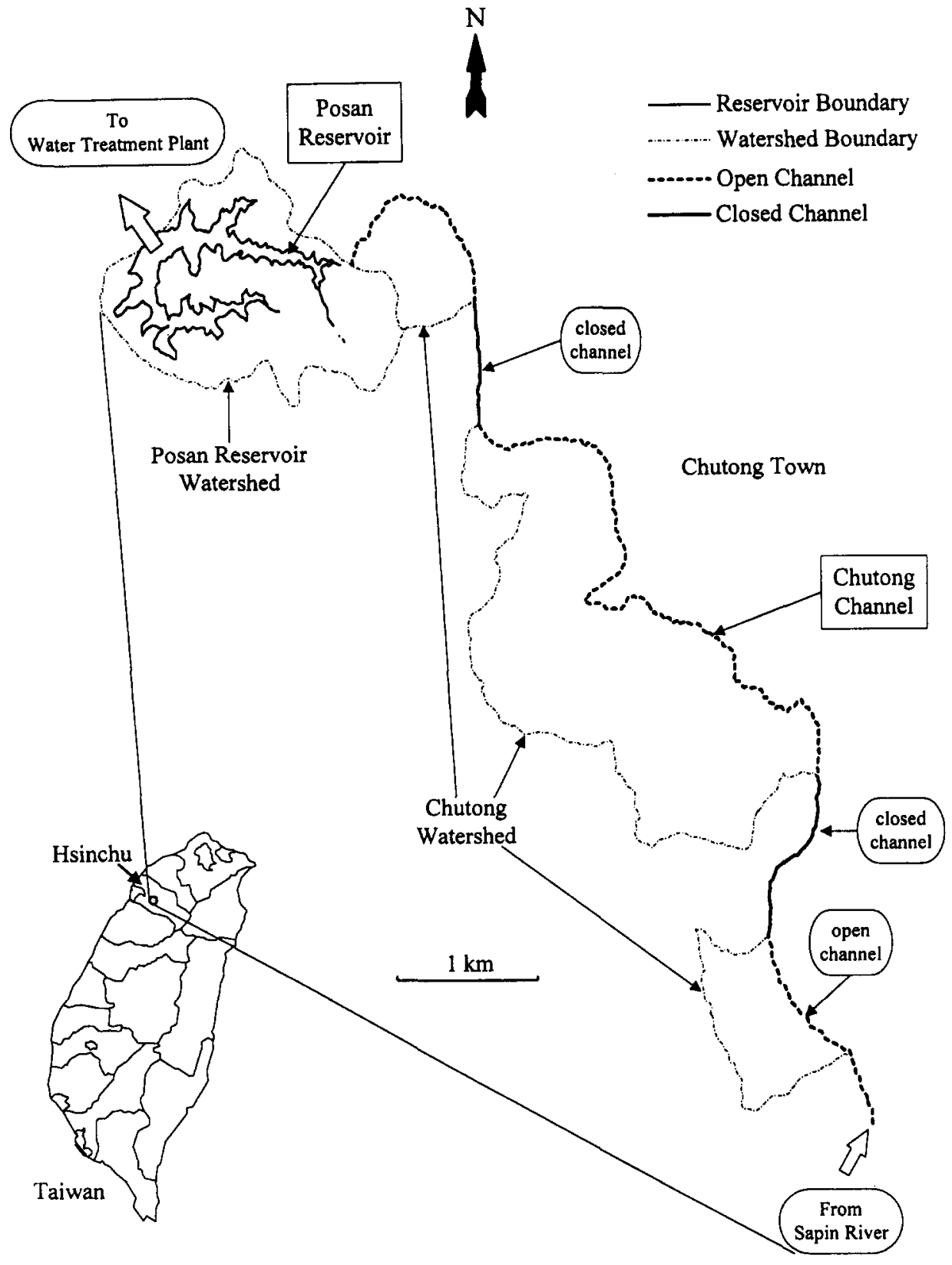

FIG. 1. Location of Posan Reservoir and Chutong Input Channel

\section{STUDY AREA}

The Posan off-stream reservoir and associated watersheds located in Hsinchu, Taiwan, ROC is the area studied. Fig. 1 illustrates the locations of the reservoir and the input channel, Chutong Channel. The major purpose of this reservoir is to serve as a public drinking-water supply; it is one of two drinking-water resources in the Hsinchu area. Chutong Channel is the input channel that transfers water from Sanpin River to the reservoir and irrigates agricultural areas within the Chutong watershed. The length of the channel is $13.36 \mathrm{~km}$, of which $6,635 \mathrm{~m}$ are closed channel and $6,501 \mathrm{~m}$ are open channel. About $1.1 \mathrm{~cm}$ of the channel flow, approximately $2.4 \mathrm{~cm}$ in total, are transported into the reservoir, whereas the remaining water is for irrigation. The total phosphorus concentration of the reservoir water body ranges between 20 and $40 \mathrm{ppb}$. According to Carlson's (1977) trophic state index, the reservoir is eutrophic and requires attention to control water quality.

Table 1 lists the major land uses in Posan and Chutong watersheds. Fertilizer applications of the four major agricultural cropping areas listed in the table contribute a significant amount of external loads to the water body, although their area fractions are small. The average amount of phosphorus fertilizer applications per hectare-year for each agricultural practice was previously surveyed as listed in Table 2 (Soil 1991). The study attempts to evaluate three different zone control strategies to alter cropping rights that would reduce fertilizer applications.

\section{NPSP SIMULATION MODEL PREPARATION AND VERIFICATION}

AGNPS (Young et al. 1994) is a physically based model developed for evaluating upstream land erosion and water quality. It is a grid-based model for single storm event simulation. Hydrology, soil erosion, nutrient, and sediment movement were computed for each model grid and for intergrid transport. Runoffs were computed according to the SCS curve number (Wischmeier and Smith 1978) and unit hydrograph methods, and peak flows were computed with equations used in a full scale model for chemical, runoff, and erosion from agricultural management systems called CREAMS (Smith and 
TABLE 1. Area Fraction (\%) of Each Land Use of Study Area

\begin{tabular}{l|c|c}
\hline \hline $\begin{array}{c}\text { Land use } \\
\text { (1) }\end{array}$ & $\begin{array}{c}\text { Chutong } \\
(2)\end{array}$ & $\begin{array}{c}\text { Posan } \\
(3)\end{array}$ \\
\hline Forest & 89.4 & 71.0 \\
Water & - & 18.7 \\
Rice & 8.1 & 0.46 \\
Orchard & 1.6 & 3.45 \\
Tea & 0.44 & 5.72 \\
Sweet potato & 0.46 & 0.67 \\
\hline \hline
\end{tabular}

TABLE 2. Average Phosphorus Fertilization Level and Production Loss per Unit Phosphorus Fertilizer Reduction for Each Major Agricultural Practice within Study Area

\begin{tabular}{l|c|c}
\hline \hline & $\begin{array}{c}\text { Average P } \\
\text { fertilization level } \\
(\mathrm{Kg} / \mathrm{ha}-\mathrm{yr})\end{array}$ & $\begin{array}{c}\text { Loss }(\$ / \mathrm{kg}) \text { per P } \\
\text { fertilizer reduction } \\
(1)\end{array}$ \\
$(2)$ & $(3)$ \\
\hline Rice & 61 & 80 \\
Sweet potato & 130 & 146 \\
Orchard & 80 & 250 \\
Tea & 55 & 90 \\
\hline
\end{tabular}

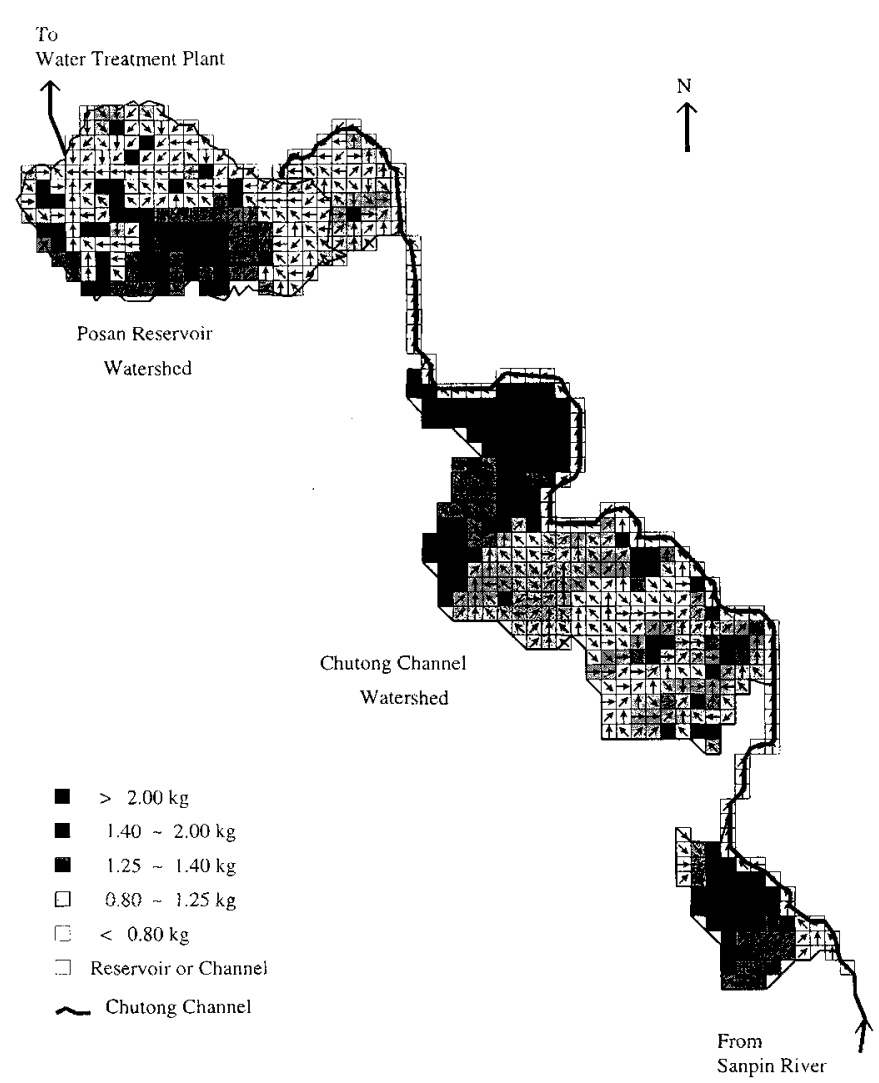

FIG. 2. Model Grids, Drainage Pattern, and Distribution of Total Phosphorus in Runoff

William 1980) or the TR55 method (USDA 1986). Upland and channel erosion from a storm event was determined primarily according to the universal soil loss equation (USLE) (Wischmeier and Smith 1978). Total nitrogen, total phosphorus (TP), and chemical oxygen demand are water quality parameters predicted by the model. In this work, TP is of primary concern because it is the limiting factor of eutrophication of the reservoir according to previous field investigations ( $\mathrm{Wu}$ et al. 1990). For AGNPS, TP is divided into two groups: dissolved TP in runoff, and sediment TP. The former group is also referred to as available TP, which is the major cause of reservoir eutrophication. The latter group includes TP absorbed or contained in sediment that is generally not easily available as a nutrient to the algae that causes eutrophication. Therefore, dissolved TP is of major concern in this study for evaluating the effectiveness of a NPSP control strategy.

\section{Model Segmentation}

In applying AGNPS, each watershed was divided into numerous rectangular grids that were not necessarily of constant size. In Taiwan, digital elevation model (DEM) data are given on a scale of $40 \times 40 \mathrm{~m}$. For convenience, the model grid cell was set in multiple sizes. The model grids and related watersheds, excluding those for the closed channel, are illustrated in Fig. 2. Each grid represents an area of $120 \times 120$ $\mathrm{m}$.

\section{Data Collection and Preparation}

Various data and parameters must be collected to apply AGNPS. Parameters for each grid were collected for cover type, soil hydrologic group, field slope length, manning coefficient, coefficients used in the USLE equation, soil condition, soil texture, fertilizer amount, fertilizer incorporation, point source information, impoundment factor, channel indicator and slope, etc., from various geographical maps, field investigations, and values suggested from previous research or the model manual. The drainage direction and land slope of each model grid were determined by a computer program (Kao 1992) from DEM data.

\section{Model Verification-Sediment}

For NPSP simulation with AGNPS, model verification was implemented in two steps: (1) verification of the modeling results with benthic sediment volume change monitored over a three-year period of $1986-88$, and (2) verification with the field-sampled results from storm events. Although AGNPS is a physically based model for which a calibration step is generally not required, many parameters used by AGNPS were collected from U.S. studies and might have been inappropriate for local conditions. For instance, the fertilizing pattern and the effect of rainfall intensity were therefore adjusted based on local watershed characteristics. The model was verified first for sediment because detailed sedimentation data were available during the period 1986-88. After model parameters were specified, the model was applied to 84 significant storm events occurring during that period. A significant event is defined as an event with rainfall larger than 0.5 in. or reaching 0.25 in. in $15 \mathrm{~min}$ (Wischmeier and Smith 1978). According to the following mass balance equation, the final accumulated sediment of the reservoir computed from the modeling results is approximately 46,518 tons, which is about $82 \%$ of the actual change monitored during the three-year period:

$$
S_{T}=\left(S_{S}+S_{C}-S_{D}\right) \cdot r+\left(S_{P}-S_{R}\right)-S_{O}
$$

where $S_{T}=$ amount of sediment accumulated in the reservoir; $S_{S}=$ sediment from Sanpin River; $S_{C}=$ total arrival sediment from the Chutong watershed; $S_{D}=$ amount of dredge of the channel; $r=$ ratio of channel water flowing into the reservoir $(1.1 / 2.4) ; S_{P}=$ sediment from the Posan watershed; $S_{R}=$ sediment removed from two sediment blockers (or big traps); and $S_{0}=$ sediment flowing out of the reservoir.

Possible reasons for the difference between simulated and monitored results include: (1) data were obtained over a threeyear period after the reservoir was established, and no investigation was carried out for the initial collapse of reservoir rims during the construction period, (2) gully sources might be inadequately simulated because no research was available to verify the applicability of the parameters suggested within AGNPS for local areas, and (3) events were simulated dis- 
cretely instead of continuously because AGNPS is limited to simulate a single event only. The result is, however, satisfactory when compared to other local results for an external (or nonpoint source) loading estimation.

\section{Model Verification - Water Quality}

The model was then verified further for sampled data from the field investigation. Field sampling for the Chutong and Posan watersheds during storm events was implemented. This sampling was difficult because of the problems in accurately predicting when a representative storm event would occur. Furthermore, a sampling must be taken within a short period for collecting effective samples to subsequently analyze the distribution of first flush pollutant loads, peak flow, and water quality parameters. Samples were collected for 5-10 min during the first hour of the event and few samples after that time period. Sampling points were selected primarily based on land uses, geographical terrain, and available manpower. One or two representative points were selected for each major land use.

Parameters of fertilizer amount and fertilizer incorporation that are related to water quality were adjusted based on values obtained from previous local research, whereas parameters related to sediment are not adjusted in this step. Fig. 3 shows the simulated TP loads from events occurring during 1987 for the Chutong watershed. A typical spatial distribution of dissolved TP load is illustrated in Fig. 2.

\section{ZONE NPSP CONTROL STRATEGIES}

The water quality of the reservoir can be improved by reducing external loads from agricultural cropping areas. The NPSP load can be reduced with various BMPs such as altering cropping rights. For management convenience, land grid cells are classified into zones; cells with similar features are put into the same zone. Within the same zone, a uniform removal policy is enforced for all NPSP sources. Three zone-control strategies, as shown in Fig. 4, are suggested in this work for the study area: (1) watershed, (2) sub-watershed, and (3) equal transport path length (ETPL). For the watershed strategy, the entire watershed is considered as a zone; i.e., the study area is divided into two zones corresponding to Posan and Chutong watersheds, respectively, under this strategy. NPSP sources within the zone are required to remove the same percentage of NPSP pollutants. This strategy is easy to implement but is

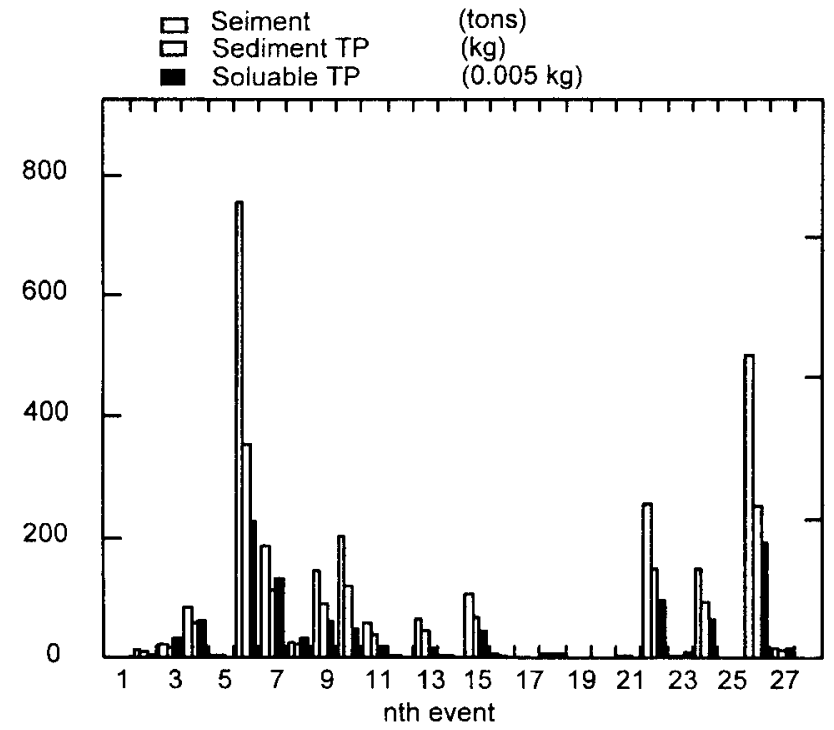

FIG. 3. AGNPS Estimated External Phosphorus Loads from Significant Events in 1988 for Chutong Watershed not cost-effective because it requires all pollution sources of a watershed to have the same removal rate. Two other zonecontrol strategies are therefore suggested to improve cost efficiency. Two criteria are used to classify the study area into subwatersheds for the second strategy: (1) within the same subwatershed, the agricultural activities are similar; and (2) all grids within the same subwatershed drain into the same outlet. With this strategy, the study area is divided into 21 zones: nine for the Posan watershed and 12 for the Chutong watershed, as shown in Fig. 5. Moreover, the impact of external loads generated from a grid on the receiving water body is generally proportional to the transport distance. The closer the grid is to the receiving water body, the higher the impact. A buffer strip near a water body is generally set based on this concept to inhibit agricultural activities. With the concept, grids with the same transport distance to the water body are grouped together to form another zone-control strategy. For this strategy, the study area is divided into 22 zones: nine for the Posan watershed and 13 for the Chutong watershed.

A control strategy with a lesser number of zones may be easier to manage. However, it is generally less cost-effective than a strategy with more zones.

\section{MULTIOBJECTIVE MODELS}

Before the proposed multiobjective models are presented at the end of this section, water quality impact coefficients, phosphorus fertilizer application, production loss caused by unit phosphorus fertilizer reduction, and the considered three objectives are described as follows.

\section{Water Quality Impact Coefficients}

The equations (Young et al. 1995) used by AGNPS to estimate soluble phosphorus in the storm runoff are listed as follows:

$$
P_{r}=\frac{\left(P_{a f}-P_{a i}\right) e^{-r_{s} e_{i}}-\left(P_{a f}-P_{a i}\right) e^{-r_{s} \cdot e_{i}-r_{r} \cdot R}}{C_{f p}}+\frac{P_{a i} r_{r} R}{C_{f p}}
$$

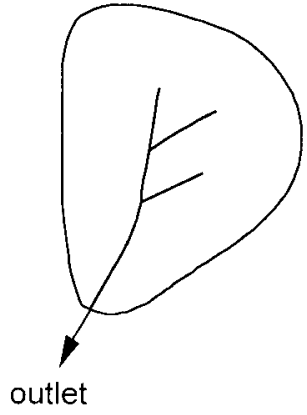

(a)

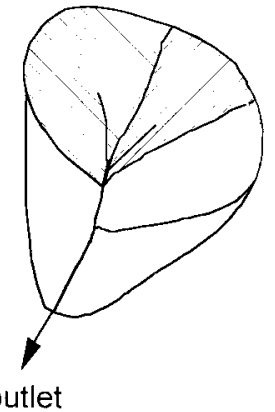

(b)

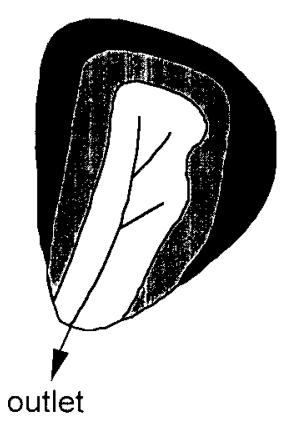

(c)
FIG. 4. Three Zone NPSP Control Strategies: (a) Watershed; (b) Subwatershed; (c) Equal Transport Path Length (ETPL) 


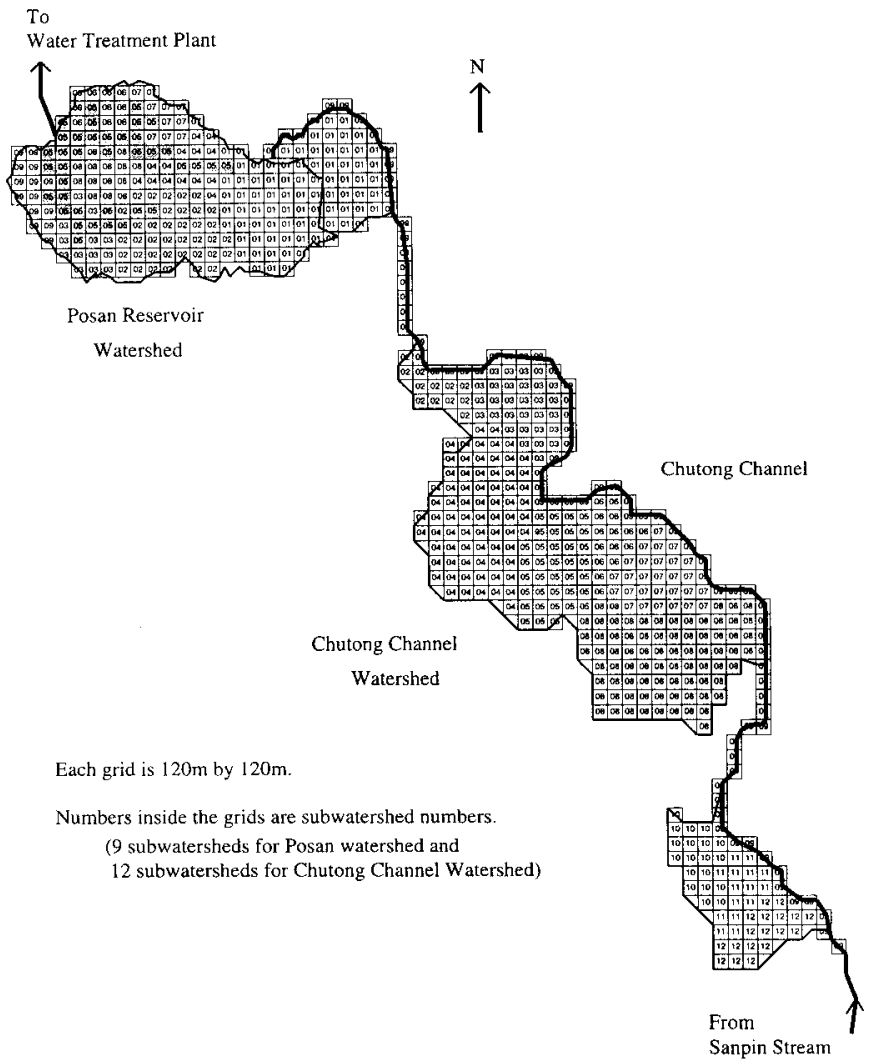

FIG. 5. Subwatersheds of Posan and Chutong Watersheds

$$
\begin{gathered}
P_{a f}=P_{s} C_{f p} \\
P_{s}=0.1 P_{p} C_{s p}+P_{f} \\
P_{f}=f_{p} f_{a}
\end{gathered}
$$

where $P_{r}=$ soluble phosphorus in the runoff; $P_{a f}=$ available phosphorus due to natural and fertilizer nutrient levels; $P_{a i}=$ available phosphorus due to the initial soil; $r_{s}=$ rate constant for downward movement of phosphorus into the soil; $e_{i}=$ effective infiltration; $r_{r}=$ rate constant for movement of phosphorus into runoff; $R=$ total storm runoff; $C_{f p}=$ porosity factor; $P_{s}=$ soluble phosphorus in the top centimeter of the original soil; $P_{p}=$ concentration of phosphorus in the pore water of the surface centimeter of soil; $C_{s p}=$ soil porosity; $P_{f}$ $=$ fertilizer phosphorus; $f_{p}=$ amount of phosphorus fertilizer applied; and $f_{a}=$ fraction of $f_{p}$ remaining in the top centimeter of the soil.

According to the equations, the pollution impact of soluble phosphorus in runoff is linearly proportional to the magnitude of fertilizer phosphorus. For each zone of the three zone-control strategies, the extent of the impact from fertilizer phosphorus reduction with respect to decreasing the NPSP loads for the water body can be expressed with a coefficient. The coefficient multiplied by the amount of the fertilizer phosphorus reduction of a zone is the phosphorus load reduction on the water body. The coefficient is determined by executing AGNPS twice (or more) with varied amounts of fertilizer phosphorus for each zone. Then, the NPSP impact coefficient of a zone is computed by dividing the soluble phosphorus change on the outlet by the difference of two varied amounts of fertilizer phosphorus. The impact coefficients are used to establish the multiobjective models for evaluating the three zone-control strategies described later in this section.

\section{Phosphorus Fertilizer Application and Production Loss Caused by Unit Reduction}

The average phosphorus fertilizer application and production loss caused by unit phosphorus fertilizer reduction for each crop have been previously estimated (Soil 1991), as listed in Table 2. These data are used to compute the total amount of phosphorus fertilizer application and total production loss (in U.S. dollars) for each zone. Table 3 summarizes the estimated average amounts of phosphorus fertilizer application of zones defined by the three zone-control strategies.

\section{Objectives: Water Quality, Cost, and Equity}

Models of engineering problems are sometimes evaluated by a single objective approach. When multiple objectives are simultaneously considered, weights are generally specified to convert them into a single measure - usually the cost. Unfortunately, the determination of the weights is quite difficult, especially for objectives that are in conflict with each other (Cohon 1978; Zeleny 1982). Different individuals may assign different weights. Thus, the solution obtained with a single objective approach may not be acceptable if the weights are not properly assigned. The multiobjective programming approach is therefore applied in varied applications [e.g., Mohan and Raipure (1992), Duckstein et al. (1994)] and has gained increasing attention in recent years.

Three objectives of water quality, cost, and equity are simultaneously considered in this study. Water quality is improved by reducing the fertilization level of NPSP sources. Table 4 lists the required external TP load reduction for achieving various TP levels, based on a mass balance computation (Kao et al. 1994). Cost of a control strategy is determined by total production loss for the amount of phosphorus fertilizer reduced. Equity is another major issue to be evaluated. The goal of a TP zone-control strategy aims to improve cost efficiency. The equity level of such a strategy is, however, worse than that of one with a uniform reduction rate. More zones are divided, and better economic impact is achieved, whereas worse equity is presented. The equity, as proposed by Brill (1979), is defined as the sum of the deviation of the fertilizer reduction rate of each zone to the average reduction rate. With this definition for equity, the farther the difference between the reduction rate and the average rate, the worse the equity, and vice versa.

\section{Formulation of Multiobjective Models}

According to the three zone-control strategies described in the previous section and the coefficients and objectives described in this section, the proposed multiobjective models for the watershed, subwatershed, and ETPL control strategies are formulated as follows:

Watershed control strategy

$$
\begin{array}{ll}
\min & \sum_{i} \sum_{k} W_{k} P_{i k} X_{i k} \quad \text { (Cost) } \\
\max & \sum_{i} I P_{i} \sum_{k} P_{i k} X_{i k} \quad \text { (Load reduction) } \\
\min \sum_{i} \sum_{k} U_{i k}+V_{i k} & \text { (Equity) }
\end{array}
$$

Subject to

$$
\begin{gathered}
0 \leq X_{i k} \leq 1 \quad \forall i, \forall k \\
\left(\sum_{i} \sum_{k} X_{i k}\right) / N=X_{\text {ave }} \\
X_{i k}-U_{i k}+V_{i k}-X_{\text {ave }}=0 \quad \forall i, \forall k \\
X_{i k} \in F_{d} \quad \forall i, \forall k
\end{gathered}
$$

where $i=$ watershed index ( 1 for Chutong Watershed and 2 for Posan Watershed); $k=$ index for a crop; $W_{k}=$ production 
TABLE 3. Phosphorus Fertllizer Application (Unit: kg/yr)

\begin{tabular}{|c|c|c|c|c|c|c|c|c|}
\hline \multirow[b]{2}{*}{$\begin{array}{c}\text { Zone index } \\
\text { (1) }\end{array}$} & \multicolumn{4}{|c|}{ Chutong Watershed } & \multicolumn{4}{|c|}{ Posan Watershed } \\
\hline & $\begin{array}{l}\text { Rice } \\
(2)\end{array}$ & $\begin{array}{l}\text { Orchard } \\
\text { (3) }\end{array}$ & $\begin{array}{l}\text { Tea } \\
(4)\end{array}$ & $\begin{array}{c}\text { Sweet potato } \\
(5)\end{array}$ & $\begin{array}{l}\text { Rice } \\
(6)\end{array}$ & $\begin{array}{l}\text { Orchard } \\
\text { (7) }\end{array}$ & $\begin{array}{l}\text { Tea } \\
(\mathbf{8})\end{array}$ & $\begin{array}{c}\text { Sweet potato } \\
\text { (9) }\end{array}$ \\
\hline \multicolumn{9}{|c|}{ (a) Watershed strategy } \\
\hline$\overline{P_{i k}}$ & $2,570.7$ & $1,090.0$ & 175.1 & 128.5 & 89.6 & $1,450.1$ & $1,482.3$ & 118.4 \\
\hline \multicolumn{9}{|c|}{ (b) Subwatershed strategy } \\
\hline $\begin{aligned} P_{i l k} & \\
l & =1 \\
l & =2 \\
l & =3 \\
l & =4 \\
l & =5 \\
l & =6 \\
l & =7 \\
l & =8 \\
l & =9 \\
l & =10 \\
l & =11 \\
l & =12\end{aligned}$ & $\begin{array}{r}49.8 \\
76.0 \\
336.7 \\
83.4 \\
1,030.5 \\
80.6 \\
85.8 \\
96.6 \\
118.8 \\
510.3 \\
- \\
102.2 \\
\end{array}$ & $\begin{array}{l}\overline{237.3} \\
180.0 \\
322.1 \\
350.6 \\
- \\
= \\
= \\
- \\
- \\
\end{array}$ & $\begin{array}{l}- \\
= \\
\overline{11.7} \\
93.3 \\
= \\
= \\
\overline{70.1} \\
=\end{array}$ & $\begin{array}{l}- \\
= \\
\overline{-} \\
88.3 \\
40.2 \\
= \\
= \\
= \\
-\end{array}$ & $\begin{array}{c}4.2 \\
29.8 \\
9.0 \\
- \\
= \\
\overline{-} \\
46.6 \\
- \\
= \\
- \\
\end{array}$ & $\begin{array}{l}75.8 \\
326.8 \\
170.5 \\
180.1 \\
431.5 \\
227.5 \\
- \\
- \\
37.9 \\
- \\
- \\
\end{array}$ & $\begin{array}{c}1, \overline{073.0} \\
168.5 \\
240.8 \\
- \\
= \\
= \\
- \\
- \\
- \\
-\end{array}$ & $\begin{array}{l}60.3 \\
- \\
- \\
- \\
\overline{24.4} \\
33.7 \\
- \\
= \\
- \\
\end{array}$ \\
\hline \multicolumn{9}{|c|}{ (c) ETPL strategy } \\
\hline $\begin{aligned} P_{i j k} & \\
j & =1 \\
j & =2 \\
j & =3 \\
j & =4 \\
j & =5 \\
j & =6 \\
j & =7 \\
j & =8 \\
j & =9 \\
j & =10 \\
j & =11 \\
j & =12 \\
j & =13\end{aligned}$ & $\begin{array}{r}517.5 \\
441.9 \\
444.7 \\
275.7 \\
164.6 \\
77.3 \\
86.1 \\
77.3 \\
195.6 \\
81.7 \\
126.2 \\
63.9 \\
18.2\end{array}$ & $\begin{array}{r}42.8 \\
60.2 \\
42.8 \\
523.8 \\
170.6 \\
\overline{189.6} \\
- \\
\overline{60.2} \\
= \\
-\end{array}$ & $\begin{array}{l}58.3 \\
70.0 \\
- \\
\overline{23.4} \\
11.7 \\
= \\
= \\
- \\
\overline{11.7}\end{array}$ & $\begin{array}{l}\bar{z} \\
\overline{40.2} \\
\bar{z} \\
\bar{z} \\
\overline{88.3} \\
\overline{-} \\
\overline{-}\end{array}$ & $\begin{array}{r}31.4 \\
8.9 \\
44.7 \\
= \\
\overline{4.6} \\
= \\
= \\
= \\
= \\
-\end{array}$ & $\begin{array}{c}947.6 \\
151.7 \\
218.1 \\
56.9 \\
- \\
37.9 \\
37.9 \\
= \\
= \\
= \\
-\end{array}$ & $\begin{array}{l}163.4 \\
- \\
268.2 \\
105.0 \\
314.9 \\
151.7 \\
344.9 \\
116.7 \\
17.5 \\
= \\
= \\
=\end{array}$ & $\begin{array}{r}32.7 \\
40.9 \\
4.4 \\
16.0 \\
= \\
\overline{24.4} \\
= \\
= \\
= \\
=\end{array}$ \\
\hline
\end{tabular}

Note: For Zone Index: $i=1$ for Chutong watershed and $i=2$ for Posan watershed; $l$ is a subwatershed index, see Fig. $5 ; j$ is a ETPL zone index; and $k$ is an index for a crop.

loss per unit phosphorus fertilizer reduction for crop $k$, as listed in the last column in Table $2 ; P_{i k}=$ amount of phosphorus fertilizer application within watershed $i$ for crop $k$, as listed in Table $3 ; X_{i k}=$ fraction of phosphorus fertilizer reduction to be determined for watershed $i$ for crop $k ; I P_{i}=$ water quality improvement impact coefficient of unit phosphorus reduction of watershed $i ; U_{i k}$ and $V_{i k}=$ negative and positive deviations of $X_{i k}$, respectively; $N=$ number of NPSP sources; $X_{\mathrm{ave}}=\mathrm{av}$ erage fertilizer reduction rate; and if $\left(X_{i k}>X_{\text {ave }}\right)$ then $V_{i k}=0$, and if $\left(X_{i k}<X_{\text {ave }}\right)$ then $U_{i k}=0$; and $F_{d}$ is the feasible space.

Subwatershed control strategy

$$
\begin{aligned}
& \min \sum_{i} \sum_{i} \sum_{k} W_{k} P_{i / k} X_{i l k} \quad \text { (Cost) } \\
& \max \sum_{i} I P_{i} \sum_{l} \sum_{k} P_{i l k} X_{i / k} \quad \text { (Load reduction) } \\
& \min \sum_{i} \sum_{l} \sum_{k} U_{i l k}+V_{i l k} \quad \text { (Equity) }
\end{aligned}
$$

Subject to

$$
\begin{gathered}
0 \leq X_{i l k} \leq 1 \quad \forall i, \forall l, \forall k \\
\left(\sum_{i} \sum_{l} \sum_{k} X_{i l k}\right) / N=X_{\text {ave }} \\
X_{i l k}-U_{i l k}+V_{i l k}-X_{\text {ave }}=0 \quad \forall i, \forall l, \forall k \\
X_{i l k} \in F_{d} \quad \forall i, \forall l, \forall k
\end{gathered}
$$

where $l=$ index for a subwatershed in Chutong and Posan watersheds.
ETPL control strategy

$$
\begin{aligned}
& \min \sum_{i} \sum_{j} \sum_{k} W_{k} P_{i j k} X_{i j k} \quad \text { (Cost) } \\
& \max \sum_{i} I P_{i} \sum_{j} \sum_{k} P_{i j k} X_{i j k} \quad \text { (Load reduction) } \\
& \min \sum_{i} \sum_{j} \sum_{k} U_{i j k}+V_{i j k} \quad \text { (Equity) }
\end{aligned}
$$

Subject to

$$
\begin{gathered}
0 \leq X_{i j k} \leq 1 \quad \forall i, \forall j, \forall k \\
\left(\sum_{i} \sum_{j} \sum_{k} X_{i j k}\right) / N=X_{\mathrm{ave}} \\
X_{i j k}-U_{i j k}+V_{i j k}-X_{\mathrm{ave}}=0 \quad \forall i, \forall j, \forall k \\
X_{i j k} \in F_{d} \quad \forall i, \forall j, \forall k
\end{gathered}
$$

where $j=$ index for an ETPL zone in Chutong and Posan watersheds.

Additional constraints may be added into the preceding models if desired. For example, the fractional phosphorus fertilizer reduction may be subject to an acceptable limit, and therefore an upper bound of the fraction may be set.

\section{RESULT AND ANALYSIS}

The multiobjective models were solved by ADBASE (Steuer 1989) to obtain the noninferior solutions, out of which no other feasible solution would yield an improvement in one objective without causing a degradation in at least one other 
objective (Cohon 1978). ADBASE is a computer package written in FORTRAN for solving multiobjective linear programs. Data of the noninferior solutions are illustrated by twodimensional trade-off plots (Figs. 6-8).

Cost is generally an important objective of an engineering problem, and it is typically desirable to show the cost-effectiveness of a solution. A reference cost is used as the basis for comparing costs of all solutions. Here the reference cost is defined as the least cost solution for the watershed control strategy. Fig. 6 summarizes the results obtained by computing the relative differences in cost of other least cost solutions for varied water quality levels to this reference cost. The top portion of the figure shows the least cost solutions of the watershed control strategy under varied equity levels. The higher the diamond in the figure implies the better the equity level. The lower portion of the figure clearly indicates that the least cost solutions of subwatershed and ETPL control strategies are more cost-effective than those of the watershed control strategy. For a TP concentration between 13 and $20 \mathrm{ppb}$, the subwatershed solution is the most cost-effective one. The subwatershed solution under TP $=15 \mathrm{ppb}$ provides the best cost reduction of $22 \%$ when compared with the reference solution; the one under $\mathrm{TP}=16 \mathrm{ppb}$ provides the second best cost reduction of $21 \%$.

Fig. 7 shows the plot for noninferior solutions under varied equity levels for a tradeoff between water quality and cost. The best equity level is achieved by setting the removal rates of all NSPS sources of a zone to be the same. With the uniform removal rate, the equity value computed by the equity objective function provided in the models is zero. As indicated in the figure, if the ideal solution approach (Cohon 1978) is ap-

TABLE 4. External Phosphorus Load Reduction Required for Varied Total Phosphorus Levels

\begin{tabular}{c|c}
\hline \hline $\begin{array}{c}\text { Total Phosphorus } \\
(\mathrm{ppb})\end{array}$ & $\begin{array}{c}\text { Phosphorus reduction } \\
(\mathrm{kg}) \\
(1)\end{array}$ \\
\hline 20 & 231 \\
19 & 269 \\
18 & 307 \\
17 & 345 \\
16 & 384 \\
15 & 422 \\
14 & 460 \\
13 & 499 \\
12 & 537 \\
\hline
\end{tabular}

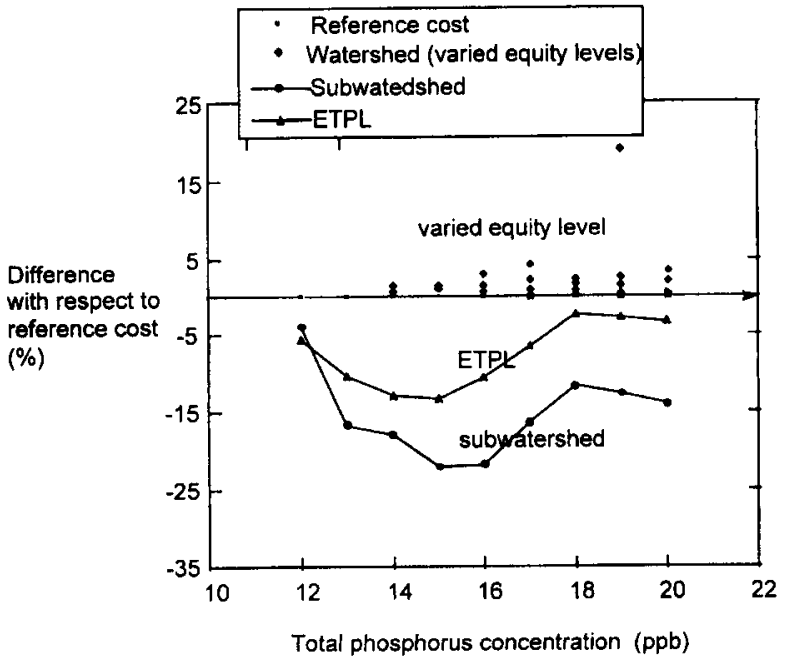

FIG. 6. Relative Differences to Reference Cost (Least Cost Solution of Watershed Control Strategy) for Least Cost Solutions of Three Control Strategies Under Varied TP Levels plied to find the best compromise solution from this plot, the subwatershed solution under TP $=15 \mathrm{ppb}$ is the best compromise-one that is closest to the ideal solution of the best achievable cost and water quality. However, the determination of the ideal solution is subjective. Different decision makers may assign different ideal solutions. Therefore, the best compromise solution may change if a different ideal solution is assigned or a decision-making method other than the ideal solution method is applied.

Fig. 8 further compares the solutions for equity levels of least cost solutions obtained under varied TP levels for each control strategy. A lower number on the $y$-axis in the figure indicates a better equity level. The least cost solution is the solution with the worst equity level. For each TP level, the solution of the watershed strategy is the one with best equity, and the solution of the subwatershed strategy is the one with least cost among solutions obtained by the three strategies. Most subwatershed solutions have a better equity level than that of the ETPL solutions, except for TP levels of 19 and 20 ppb. For TP levels between 12 and $18 \mathrm{ppb}$, subwatershed solutions dominate the ETPL solutions for both cost and equity

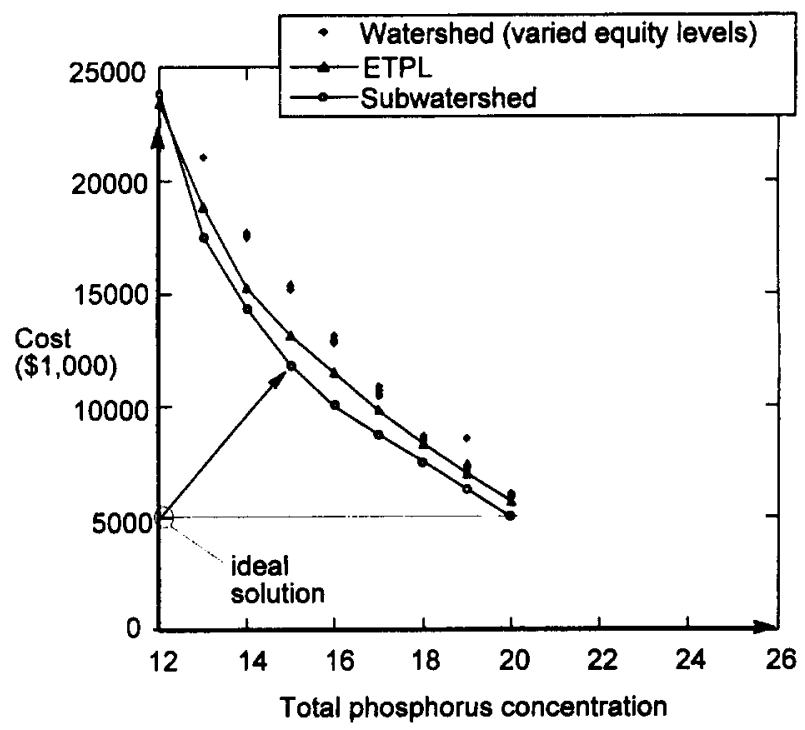

FIG. 7. Tradeoff between Water Quality and Cost (with Varied Equity Levels)

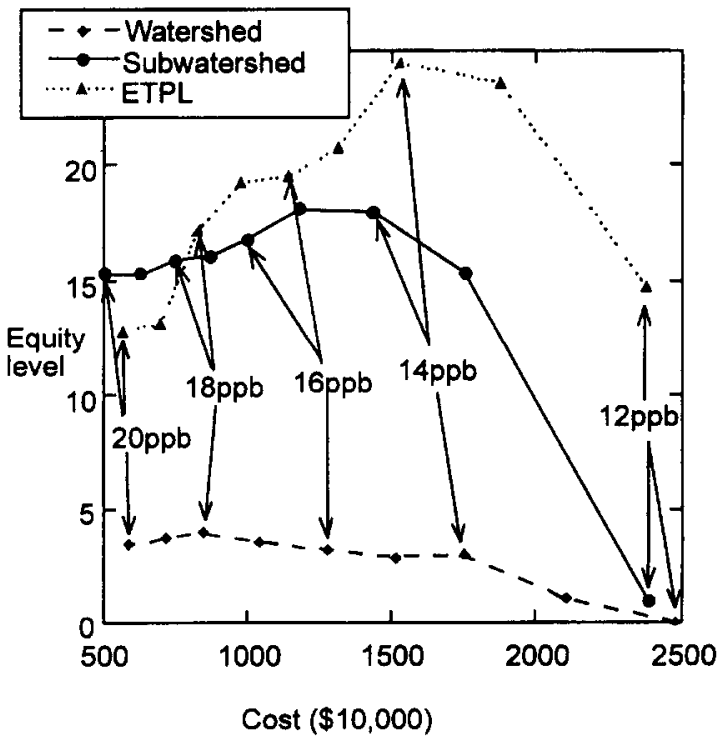

FIG. 8. Comparison of Equity Levels and Water Quality of Least Cost Solutions under Varied TP Levels 
levels. In summary, solutions for the subwatershed control strategy have more advantages than others for the study area.

\section{CONCLUSION}

Eutrophication due to excessive external nutrient loads significantly deteriorates the water quality of a reservoir. The water quality manager is seeking an appropriate control strategy to remedy the water quality of a water body, especially for a public water supply source. A modeling approach is typically adopted for evaluating NPSP control strategies. For an offstream reservoir, the modeling procedure is, however, more complex than that for a general one. Special data manipulation is required to handle the subwatersheds of open and closed channel portions of the input channel. External load control must be implemented on both the watershed of the reservoir and the watershed of the channel. A two-step modeling procedure is applied to establish an NPSP model for the study area. The model is then utilized to determine various data for setting up the proposed multiobjective models for evaluation of three different zone-control strategies based on the three objectives of water quality, cost, and equity. The proposed models, while considering multiple objectives, are expected to improve the comparison and evaluation of various solutions for attainable water quality levels, cost-effectiveness, and equity levels. The best compromise NPSP control strategy is therefore likely to be established.

In future work, other important NPSP parameters such as sediment erosion and pesticide applications are to be included into the model to simultaneously evaluate multiple objectives for multiple NPSP loads. However, impact coefficients of NPSP sources on the receiving water body for sediment erosion and pesticide are generally nonlinear and discrete instead of linear. A more complex modeling approach such as multiobjective mix-integer programming or dynamic programming must be applied to resolve the new model. Such a model is being developed. Furthermore, exploring an appropriate decision-making process for obtaining a widely acceptable, best compromise solution from noninferior alternatives is a challenging task, although the ideal solution method described in this article demonstrated a simple approach to determine a possible compromise solution. Interactions with decision makers, if possible, for evaluating noninferior solutions will take place to obtain necessary preference information for selecting the final solution.

\section{ACKNOWLEDGMENT}

The writers would like to thank National Science Council, ROC, for providing partial financial support of this research under Grant No. NSC 82-0410-E-009-382.

\section{APPENDIX. REFERENCES}

Bouzaher, A., Braden, J. B., and Johnson, G. V. (1990). "A dynamic programming approach to a class of nonpoint source pollution control problems." Mgmt. Sci., 30(1), 1-15.
Bouzaher, A., Braden, J. B., Johnson, G. V., and Murley, S. E. (1994). "An efficient algorithm for nonpoint source pollution management problems." J. Operational Res. Soc., 45(1), 39-46.

Braden, J. B., Johnson, G. V., Bouzaher, A., and Miltz, D. (1989). "Optimal spatial management of agricultural pollution." Am. Agric. Economics Assn., 71(2), 404-413.

Brill, E. D. Jr. (1979). "The use of optimization models in public sector planning." Mgmt. Sci., 25(5), 413-422.

Carlson, R. E. (1977). "A tropic state index for lakes." Limnology and Oceanography, 22(2), 361-369.

Cohon, J. L. (1978). Multiobjective programming and planning. Academic Press, Inc., New York, N.Y.

Duckstein, L., Treichel, W., and Magnouni, S. E. (1994). "Ranking ground-water management alternatives by multicriterion analysis." $J$. Water Resour. Plng. and Mgmt., ASCE, 120(4), 546-565.

Kao, J.-J. (1992). "Determining drainage pattern using DEM data for nonpoint source pollution water quality modeling." Water Sci. and Technol., 26(5-6), 1431-1438.

Kao, J.-J., Tsai, C.-C., and Bau, S.-F. (1994). "Development of analysis models for total mass load based discharge programs." Technical Rep. No. NSC 81-0410-E009-382, Nat. Sci. Council, Taipei, ROC.

Kozloff, K., Taff, S. J., and Wang, Y. (1992). "Microtargeting the acquisition of cropping rights to reduce nonpoint source water pollution.' Water Resour. Res., 28(3), 623-628.

Milon, J. W. (1987). "Optimizing nonpoint source controls in water quality regulation.' Water Resour. Bull., 23(2), 387-396.

Mohan, S., and Raipure, D. M. (1992). "Multiobject analysis of multireservoir system." J. Water Resour. Plng., and Mgmt., ASCE, 118(4), $356-370$.

Smith, R. E., and William, J. R. (1980). "Simulation of surface water hydrology." CREAMS, A field scale model for chemicals, runoff, and erosion from agricultural management systems; Conservation Res. Rep. No. 26, W. Knisel, ed., U.S. Dept. of Agric., Sci., and Educ. Admin.

Smolen, M. D., Jennings, G. D., Huffman, R. L., Novotny, V., Cohen, R. R. H., and Gorman, J. (1990). "Nonpoint source impact assessment." WPCF Res. Found. Rep. No. 90-5, CH2M Hill, Inc.

Soil management manual. (1991). Soil Investigation Ctr., National Chung Hsin University, Taichung, ROC (in Chinese).

Steuer, R. E. (1989). ADBASE operating manual. Dept. of Mgmt. Sci. and Info. Technol., Univ, of Ga., Athens, Ga.

United States Department of Agriculture (USDA). (1986). "Urban hydrology for small watersheds." Tech. Release 55, Engrg. Div., Soil Conservation Service, Washington, D.C.

U.S. Environmental Protection Agency (USEPA). (1992), "Managing Nonpoint Source Pollution." EPA-50619-90, Office of Water, Washington, D.C.

Wischmeier, W. H., and Smith, D. D. (1978). Predicting rainfall erosion losses. Agric. Handbook 537. USDA, Washington, D.C.

Wu, S.-C., Wang, M.-S., and Chen, S.-Y. (1990). "Mass balance and control strategy for reservoirs in Taiwan." Rep. Prepared for ROC $E P A$, Taipei, ROC (in Chinese).

Young, R. A., Onstad, C. A., Bosch, D. D., and Anderson, W. P. (1994), "Agricultural non-point source pollution model." Version 4.03 AGNPS user's guide. USDA-ARS, Morris, Minn.

Young, R. A., Onstad, C. A., Bosch, D. D., and Anderson, W. P. (1995). Nutrient Information for AGNPS. USDA-ARS, Morris, Minn.

Zeleny, M. (1982). Multiple criteria decision making. McGraw-Hill Book Co., Inc., New York, N.Y.

Ziari, H. A., and McCarl, B. A. (1995). "A nonlinear mixed integer program model for evaluating runoff impoundments for supplemental irrigation." Water Resour. Res., 31(6), 1585-1594. 